\title{
Mobilidade e desigualdades de acesso aos serviços urbanos nas periferias de Belo Horizonte: um estudo qualitativo
}

\author{
Mobility and inequalities in access in the suburban areas of Belo Horizonte
}

Eugênia Dória Viana Cerqueira

Université Paris 1 Panthéon-Sorbonne, França eugeniadoria@gmail.com

\begin{abstract}
Resumo
Nas últimas duas décadas, enfatiza-se que as periferias metropolitanas têm testemunhado uma inflexão do processo tradicional de expansão urbana, com o surgimento de estruturas policêntricas e multifuncionais, que suscitam uma reestruturação das práticas de mobilidade. Este artigo tem como objetivo compreender as desigualdades de mobilidade nas periferias da Região Metropolitana de Belo Horizonte (Brasil), em um contexto de diversificação socioespacial dos espaços em questão. Expõese os principais resultados de uma série de entrevistas semiestruturadas, que apontam para uma articulação entre novas práticas de mobilidade, moldadas pela emergência de estruturas póssuburbanas, e intensas desigualdades, decorrentes do modelo de urbanização centro-periferia.
\end{abstract}

Palavras-chave: Mobilidade; Expansão Urbana; Periferias; Acessibilidade; Belo Horizonte.

\begin{abstract}
The recent literature on post-suburbia emphasizes that, over the past two decades, low-density areas worldwide have experienced a shift of the traditional suburban model through the emergence of polycentric and multifunctional structures, new travel behaviour and mobility trends, social diversification and the relocation of activities. This paper seeks to grasp inequalities in mobility and travel patterns in the metropolitan areas of the Metropolitan Region of Belo Horizonte (Brazil) in the diversification of the urban fringes. The key results of a set of semi-structured interviews underline that although new mobility patterns may be associated with the emergency of post-suburbian structures, significant inequalities are still observed.
\end{abstract}

Keywords: Travel-behavior; Urban Sprawl; Urban Amenities; Accessibility; Belo Horizonte.

\section{INTRODUÇÃO}

A questão da mobilidade urbana, compreendida como "um atributo relacionado aos deslocamentos realizados por indivíduos nas suas atividades de estudo, trabalho, lazer e outras" (MAGAGNIN, 2008, p.26), tem sido amplamente discutida na última década, notadamente em razão dos seus impactos, não somente no que concerne o ambiente urbano, mas também as desigualdades socioespaciais. Com efeito, a mobilidade emerge como um dos principais fatores de inserção na sociedade, corroborando a exclusão de determinadas categorias da população, que possuem capacidade limitada de se deslocar (BACQUÉ; FOL, 2007). As desigualdades relativas à mobilidade são particularmente proeminentes em metrópoles de países em desenvolvimento, em decorrência do 
rápido e desordenado processo de expansão urbana, que moldou historicamente as cidades em questão.

As condições de mobilidade e de acesso aos serviços nas periferias urbanas são caracterizadas por desigualdades estruturais e pela intensa dependência do centro urbano. Dessa forma, os moradores das periferias urbanas que não se inscrevem nos padrões flexíveis propiciados pela mobilidade automóvel (DUPUY, 1999) são confrontados com situações de exclusão socioespacial em termos de deslocamento e de acesso às amenidades urbanas (ROUGÉ, 2005). Assim, uma estrutura de mobilidade inadequada pode causar ou intensificar o grau de exclusão social de um dado grupo populacional. A mobilidade consiste, então, em um importante instrumento de exercício do Direito à Cidade (LEFEBVRE, 1968), tal qual estabelecido no Estatuto da Cidade, atuando como mecanismo de acesso a serviços, emprego, cultura, lazer, educação e bens. Sob essa ótica, a partir de 2012, o Estatuto da Cidade impõe o desenvolvimento de Planos de Mobilidade a municípios acima de 20.000 habitantes, mesmo critério aplicado para os Planos Diretores. A referida diretriz tem como objetivo assegurar o Direto à Cidade, princípio norteador do Estatuto da Cidade, assim como mitigar as desigualdades históricas no acesso aos equipamentos urbanos. Entretanto, a grande maioria das metrópoles brasileiras encontra uma miríade de obstáculos no desenvolvimento de soluções e gestão da mobilidade no âmbito metropolitano, notadamente no que se refere aos municípios periféricos, tradicionalmente desprovidas em infraestrutura de transporte público (NETO; FILHO, 2015).

Nas últimas décadas, mudanças na estrutura territorial das metrópoles brasileiras apontam na direção de formas de urbanização cada vez mais dispersas e diversificadas, em consônancia com as tendências vigentes no contexto internacional (REIS FILHO, 2006 ; LIMONAD; COSTA, 2015). A expansão periférica vem se tornando cada vez mais complexa em termos de uso do solo e das atividades que abrigam, associando diferentes tipologias residenciais a shopping centers, centros de lazer, equipamentos de educação etc. O poder de atração das áreas centrais em termos de deslocamentos cotidianos compete com a emergência de centralidades secundárias nas periferias das aglomerações (MENDONÇA et al., 2004), traçando novos padrões potenciais de mobilidade urbana e de acesso aos serviços.

Atualmente, constata-se uma grande diversidade de processos que se superpõem nos vetores de expansão urbana da Região Metropolitana de Belo Horizonte, contribuindo com uma redefinição gradual do padrão excludente centro-periferia que pautou o processo de urbanização das cidades brasileiras (COSTA; MENDONÇA, 2015 ; ALMEIDA et al., 2017). Esse novo tecido socioterritorial periférico tem surgido sobretudo a partir da expansão de segmentos da população vistos como solváveis pelo mercado formal e dos crescentes investimentos habitacionais em áreas até recentemente vistas apenas como redutos de irregularidade urbanística. As transformações urbanas 
descritas configuram estruturas complexas em termos de uso do solo, distribuição das populações e atividades. Algumas investigações argumentam que, ainda que as metrópoles em questão sejam pautadas pelo modelo histórico de urbanização centro-periferia, a crescente dispersão de atividades e a emergência de centros secundários nas periferias poderiam desenhar padrões de mobilidade mais complexos e menos dependentes dos centros urbanos (LIMONAD; COSTA, 2015).

Nesse sentido, o desenvolvimento das centralidades periféricas constituiu um ponto norteador do Plano de Diretor de Desenvolvimento Integrado (PDDI) da RMBH, na medida em que a proposta territorial visou a uma descentralização concentrada e seletiva das atividades e dos investimentos urbanos, em contraposição à tendência pautada na concentração excessiva em um único centro e na expansão fragmentada e descontínua da mancha urbana. A diretriz de combate à dispersão urbana exprime uma estratégia de constituição de um tecido metropolitano mais compacto e coeso e do aumento das densidades junto às centralidades e aos pontos de maior acessibilidade (TONUCCI FILHO; MEDEIROS DE FREITAS, 2019). Em paralelo, em 2018, iniciou-se a elaboração do Plano de Mobilidade da Região Metropolitana de Belo Horizonte, tendo como objetivo apresentar estudos para definição de políticas e de uma carteira de projetos e ações para melhoria das condições de mobilidade urbana na RMBH e sua sustentabilidade.

Sob essa ótica, o presente artigo tem como objetivo analisar as desigualdades de mobilidade e acesso aos serviços nas periferias da Região Metropolitana de Belo Horizonte (RMBH), em um contexto recente de evolução desses espaços. Embora as premissas legislativas supracitadas ecoem os argumentos sustentados pelo Estatuto da Cidade, poucas investigações avaliaram, em contexto recente, as condições mobilidade dos habitantes das periferias de Belo Horizonte, de forma detalhada (VIANA CERQUEIRA, 2018 ; LESSA; LOBO; CARDOSO, 2019). A questão levantada é particularmente pertinente na $\mathrm{RMBH}$, que demonstra uma carência de infraestrutura de transporte público sobre trilhos e uma intensa dependência do sistema de ônibus, agravando fatores como congestionamento, poluição e dificuldades de acesso aos serviços. Na medida em que a mobilidade se torna, cada vez mais, um elemento imperativo para a inclusão social e fator capital na luta pelo Direto à Cidade, deve-se questionar as desigualdades referentes às diversas camadas da população.

Sob essa perspectiva, levanta-se a hipótese de que a diversificação das estruturas periféricas nas últimas duas décadas, poderia acarretar uma potencial reestruturação dos padrões de mobilidade urbana (PHELPS, 2018). Ainda que o modelo centro-periferia conserve seus atributos definidores nas metrópoles brasileiras, preconiza-se uma menor dependência do centro urbano em termos de deslocamentos diários (DUREAU et al., 2015). Em consonância com investigações recentes (LIMONAD; COSTA, 2015 ; BERROIR et al., 2017 ; HARRIS; VORMS, 2017 ; LUKAS; LÓPEZMORALES, 2018), aponta-se que consolidação de estruturas policêntricas e centralidades periféricas poderiam potencialmente moderar o tempo e a distância dos deslocamentos dos habitantes das 
periferias urbanas, além de reduzir a relação histórica de dependência entre centro e periferias. Nesse sentido, visa-se dissecar as desigualdades de mobilidade na RMBH, aferindo os eventuais impactos das evoluções socioespaciais das periferias urbanas nos deslocamentos cotidianos de seus habitantes.

$\mathrm{O}$ artigo alicerça-se em três dimensões principais. Primeiramente, detalha-se as condições de mobilidade nas periferias das grandes metrópoles, buscando abordar as principais transformações observadas nos espaços em questão nas últimas décadas. Evidencia-se, igualmente, as principais características das novas estruturas socioespaciais verificadas nas periferias de Belo Horizonte. Em seguida, expõe-se a metodologia de estudo, ressaltando a utilização crescente de métodos qualitativos em pesquisas de mobilidade. Por fim, procura-se apreciar os principais resultados das entrevistas semi-estruturadas, que assinalam as diversas preferências, obstáculos e estratégias de mobilidade dos habitantes das periferias metropolitanas.

\section{AS TRANSFORMAÇÕES RECENTES DAS PERIFERIAS DE BELO HORIZONTE: QUAIS POSSÍVEIS IMPACTOS SOBRE A MOBILIDADE?}

As desigualdades de mobilidade e acesso aos equipamentos cotidianos são particularmente acentuadas nas grandes cidades da América Latina, onde o processo desenfreado de urbanização resultou na escassez de serviços e infraestrutura de transporte, sobretudo nos espaços periféricos. A região metropolitana de Belo Horizonte se destaca como uma metrópole típica brasileira, apresentando uma estrutura socioespacial que corresponde ao sistema metropolitano nacional (ANDRADE; MENDONÇA; DINIZ, 2015). Assim como a maioria das cidades brasileiras, Belo Horizonte apresentou um acelerado crescimento demográfico desde meados do século passado, notadamente nas periferias metropolitanas.

A estrutura urbana altamente homocêntrica da metrópole oferece condições inadequadas de mobilidade e acesso aos equipamentos cotidianos, exigindo longos deslocamentos dos habitantes das periferias urbanas para alcançar oportunidades de emprego e consumo (LESSA; LOBO; CARDOSO, 2019). Como resultado, a região tem apresentado distorções no sistema de transportes metropolitano, afetando a mobilidade de pessoas e mercadorias. Enquanto a população da RMBH cresceu 9.9\% no período de 2010 a 2020 (IBGE), a frota geral de veículos privados teve um crescimento de 70\% (DENATRAN, 2020), sem o devido investimento na infraestrutura e no sistema de transporte público e sem uma política que promovesse o planejamento e gestão integrada dos diversos meios de transporte a nível metropolitano. Embora um sistema de transporte rápido de ônibus (BRT) tenha sido recentemente implementado para a Copa do Mundo de 2014, o sistema de transporte público permanece altamente insuficiente em escala metropolitana, especialmente para os moradores das periferias metropolitanas.

A literatura recente sobre a pós suburbia (PHELPS, 2018 ; HARRIS; VORMS, 2017) aponta 
que, em uma escala global, os modelos clássicos das periferias urbanas vêm se reconfigurando, dando lugar para estruturas policêntricas e multifuncionais, pautadas pela reestruturação das lógicas de mobilidade e pela crescente diversificação do mercado imobiliário. Essas novas dinâmicas periféricas alicerçam-se em uma implosão da oposição dialética entre centro e periferia, suscitando o questionamento do estereótipo das periferias como territórios homogêneos e precários, adjacentes aos centros urbanos (LE GOIX, 2016). Nas metrópoles brasileiras, mudanças na estrutura territorial apontam na direção de formas de urbanização cada vez mais dispersas e diversificadas, em consonância com as tendências vigentes no contexto internacional (REIS FILHO, 2006). A expansão periférica vem se tornando cada vez mais complexa em termos de uso do solo e das atividades que abrigam, associando diferentes tipologias residenciais a shopping centers, centros de lazer, equipamentos de educação etc. O poder de atração das áreas centrais, em termos de deslocamentos cotidianos, compete com a emergência de centralidades secundárias nas periferias das aglomerações (MENDONÇA; PERPÉTUO; VARGAS, 2004).

Atualmente, constata-se uma grande diversidade de processos que se superpõem nos vetores de expansão urbana da Região Metropolitana de Belo Horizonte, contribuindo com uma redefinição gradual do padrão excludente centro-periferia que pautou o processo de urbanização das cidades brasileiras (COSTA; MENDONÇA, 2015). Esse novo tecido socioterritorial periférico tem surgido sobretudo a partir da expansão de segmentos da população vistos como solváveis pelo mercado formal e dos crescentes investimentos habitacionais em áreas até recentemente vistas apenas como redutos de irregularidade urbanística. No eixo sul da RMBH, a produção de loteamentos fechados com vantagens ambientais para a localização de habitação das populações de alta renda intensificase nos municípios de Nova Lima e Brumadinho. Em alguns municípios da região industrial, como Contagem e Betim, verifica-se o espraiamento de segmentos das classes médias em consonância com a expansão das fronteiras do segmento concorrencial do mercado imobiliário. No vetor Norte da Região Metropolitana, uma região de tradicional urbanização popular, fatores como o aumento geral da renda real e de acesso ao crédito contribuem com o surgimento de novos segmentos de mercado destinados às classes de baixa renda (COSTA; MENDONÇA, 2010). Além disso, a implantação de um novo Centro Administrativo no eixo norte da aglomeração, abrigando as instituições públicas do governo estadual, promove uma inflexão das dinâmicas do mercado imobiliário. Nesse sentido, espaços anteriormente determinados pela ocupação popular são submetidos a uma série de investimentos, que acarretam a valorização de tais áreas. 


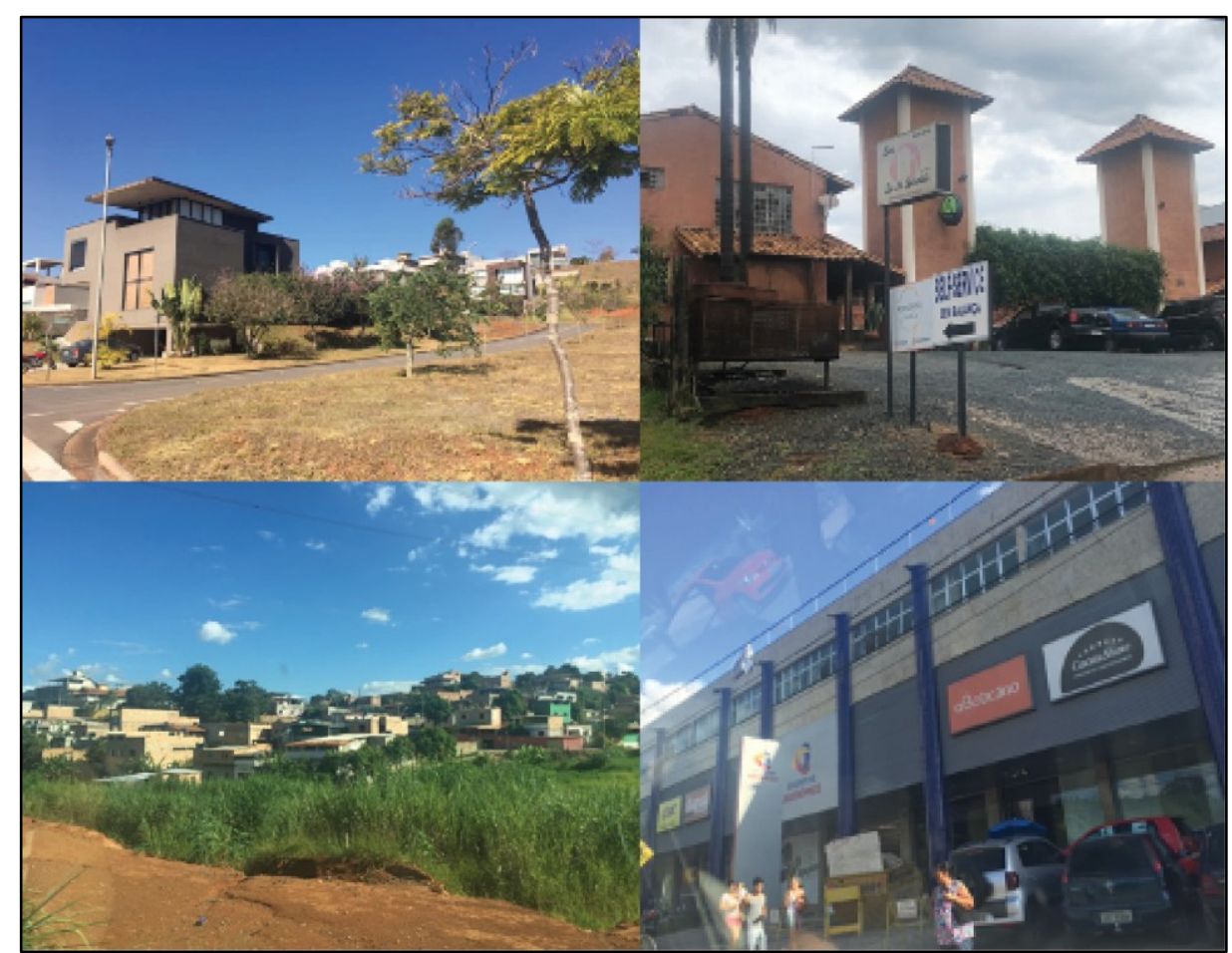

Figura 1 - A diversidade das periferias de Belo Horizonte.

Fonte: Autora (2017). À esquerda acima: Condomínio Alphaville Lagoas dos Ingles, em Nova Lima. À direita acima: comércio local no Vale do Sol, Nova Lima. À esquerda abaixo: periferias populares em Ribeirão das Neves. À direita abaixo: centro comercial, Ribeirão das Neves.

O Plano Diretor de Desenvolvimento Integrado (PDDI) da RMBH, elaborado em 2011, possui como uma de suas principais premissas a consolidação de centralidades periféricas préexistentes ou em desenvolvimento, levando em conta a diversidade crescente das periferias metropolitanas. Preconiza-se o desenvolvimento de uma mobilidade metropolitana, organizada em rede, que dissemine ao máximo no território o acesso às oportunidades. Assim, ainda que a metrópole em questão seja pautada pelo modelo histórico de urbanização centro-periferia, aponta-se que a crescente dispersão de atividades e a emergência de centros secundários nas periferias poderiam desenhar padrões de mobilidade mais locais e menos dependentes do município de Belo Horizonte, evitando longos deslocamentos diários no acesso às atividades (LIMONAD; COSTA, 2015).

A figura abaixo (Figura 2), ilustra a distribuição e densidade de serviços e equipamentos na Região Metropolitana de Belo Horizonte ${ }^{1}$, em 2020. A imagem retifica os diagnósticos apresentados no PDDI na década anterior, identificando uma série de centralidades secundárias nas periferias da metrópole, que conjugam antigas centralidades periféricas históricas e centralidades mais recentes, tais como o bairro Jardim Canadá, em Nova Lima. Embora o centro de Belo Horizonte, assim como as conurbações de Betim e Contagem se destaquem como os munícipios possuindo a maior densidade de serviços, observa-se igualmente a presença de centralidade periféricas em áreas de menor densidade, como nova Lima, Lagoa Santa e Ribeirão das Neves.

\footnotetext{
${ }^{1}$ Utilizou-se o método “densidade de Kernel” para a elaboração do mapa.
} 


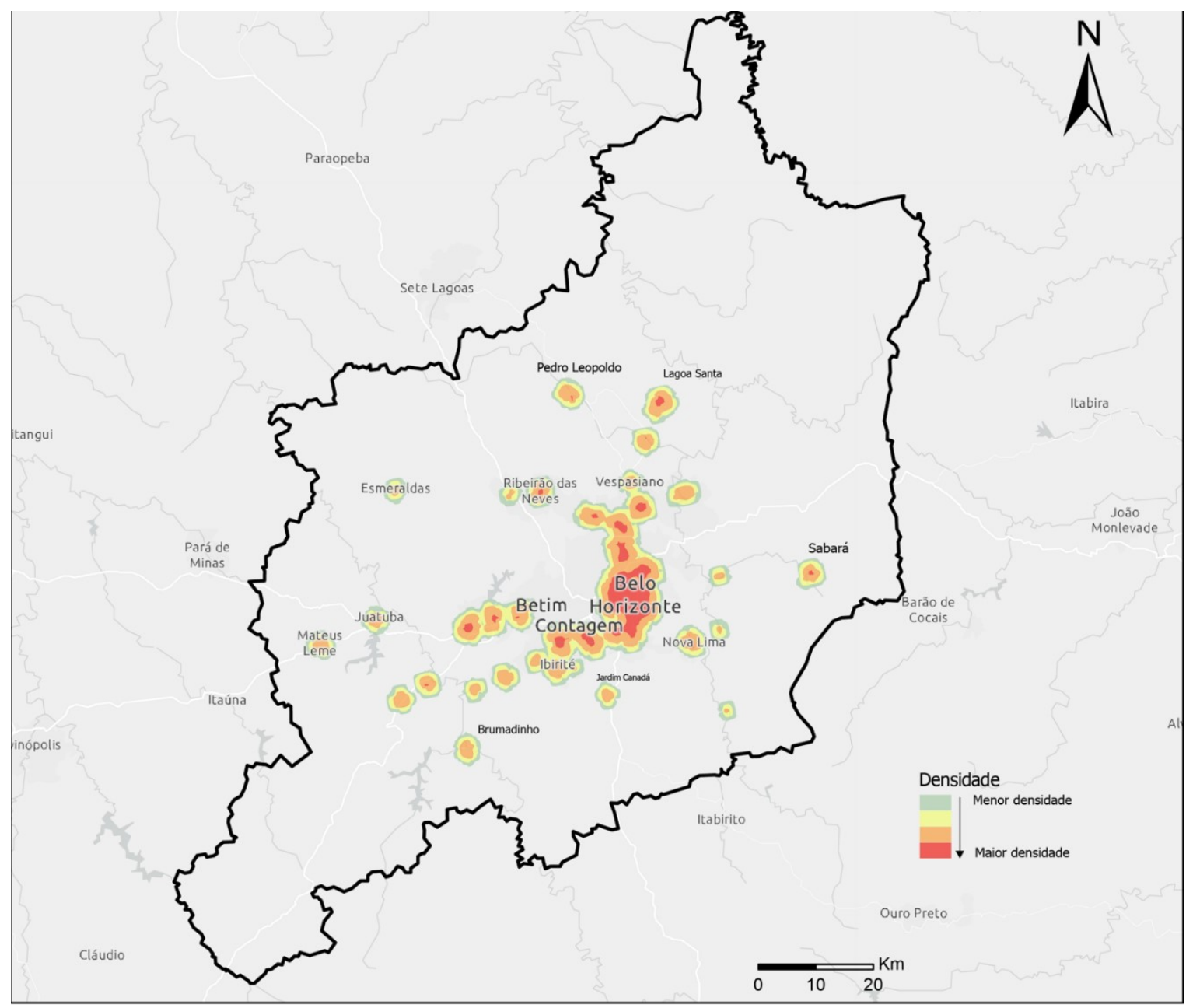

Figura 2 - Densidade de equipamentos e centralidades na RMBH.

Fonte: Autora, Google Places of Interest (2020).

Nesse sentido, o espaço urbano-metropolitano de Belo Horizonte traduz o acúmulo dos diversos tempos e elementos da urbanização da metrópole, nos quais centro e periferia se transformam e se interpenetram, ao mesmo tempo conservando, na essência, seus atributos definidores (LIMONAD; COSTA, 2015). Questiona-se, assim, se as desigualdades de mobilidade na RMBH e os eventuais impactos da diversificação socioespacial das periferias nas duas últimas décadas sobre os deslocamentos e acesso aos serviços cotidianos. Sob essa ótica, a presente investigação propõe o desenvolvimento de uma série de entrevistas semi-estruturadas, no intuito de aferir as condições, estratégias e obstáculos de mobilidade na RMBH.

\section{MATERIAIS E MÉTODOS}

A mobilidade e o acesso aos serviços urbanos dificilmente podem ser interpretados como simples atividades mecânicas cotidianas, uma vez que envolvem uma série de componentes subjetivos e preferências pessoais. Nas últimas décadas, estudos baseados em investigações qualitativas procuraram dissecar experiências individuais de mobilidade, ressaltando as estratégias e lógicas de decisão intrínsecas à mobilidade (CLIFTON, 2004 ; FOL, 2010; BERROIR et al., 2017). 
A complexidade dos padrões de mobilidade exige uma compreensão profunda das percepções, preferências e comportamentos individuais. Sob essa perspectiva, os métodos qualitativos têm sido considerados como mecanismos importantes para explorar os padrões de mobilidade, permitindo, muitas vezes, uma compreensão mais detalhada das lógicas por trás dos comportamentos de mobilidade do que os tradicionais questionários fechados (CLIFTON; HANDY, 2001). Com efeito, nos últimos anos, diversas pesquisas de mobilidade em todo o mundo têm adotado questões relativas às percepções e experiências subjetivas dos usuários, no intuito de aprimorar a qualidade e a eficiência dos sistemas de transporte.

O presente estudo relata os principais resultados de um conjunto de 30 entrevistas semiestruturadas realizadas em quatro municípios situados nas periferias urbanas da Região Metropolitana de Belo Horizonte, possuindo características socioespaciais diversas (Figura 2). Onze participantes foram entrevistados em Nova Lima, município do vetor sul da metrópole, que apresentou um crescimento expressivo de loteamentos fechados destinados moradores de alta renda nas últimas duas décadas. Já o município de Ribeirão das Neves, tradicionalmente de baixa renda, responde por um terço das entrevistas. O último terço das entrevistas foi realizado em Vespasiano e Confins, dois municípios tradicionalmente de baixa renda que sofreram mudanças significativas nas últimas décadas, como a implantação do novo Complexo Administrativo Estadual e a reforma do Aeroporto Metropolitano. As perguntas norteadoras das entrevistas gravitam em torno dos principais deslocamentos realizados pelos indivíduos entrevistados, assim como as estratégias de acesso aos serviços e preferências pessoais de mobilidade. Vale, igualmente, ressaltar a natureza exploratória das entrevistas realizadas, que não pretendem uma representatividade de amostragem quantitativa.

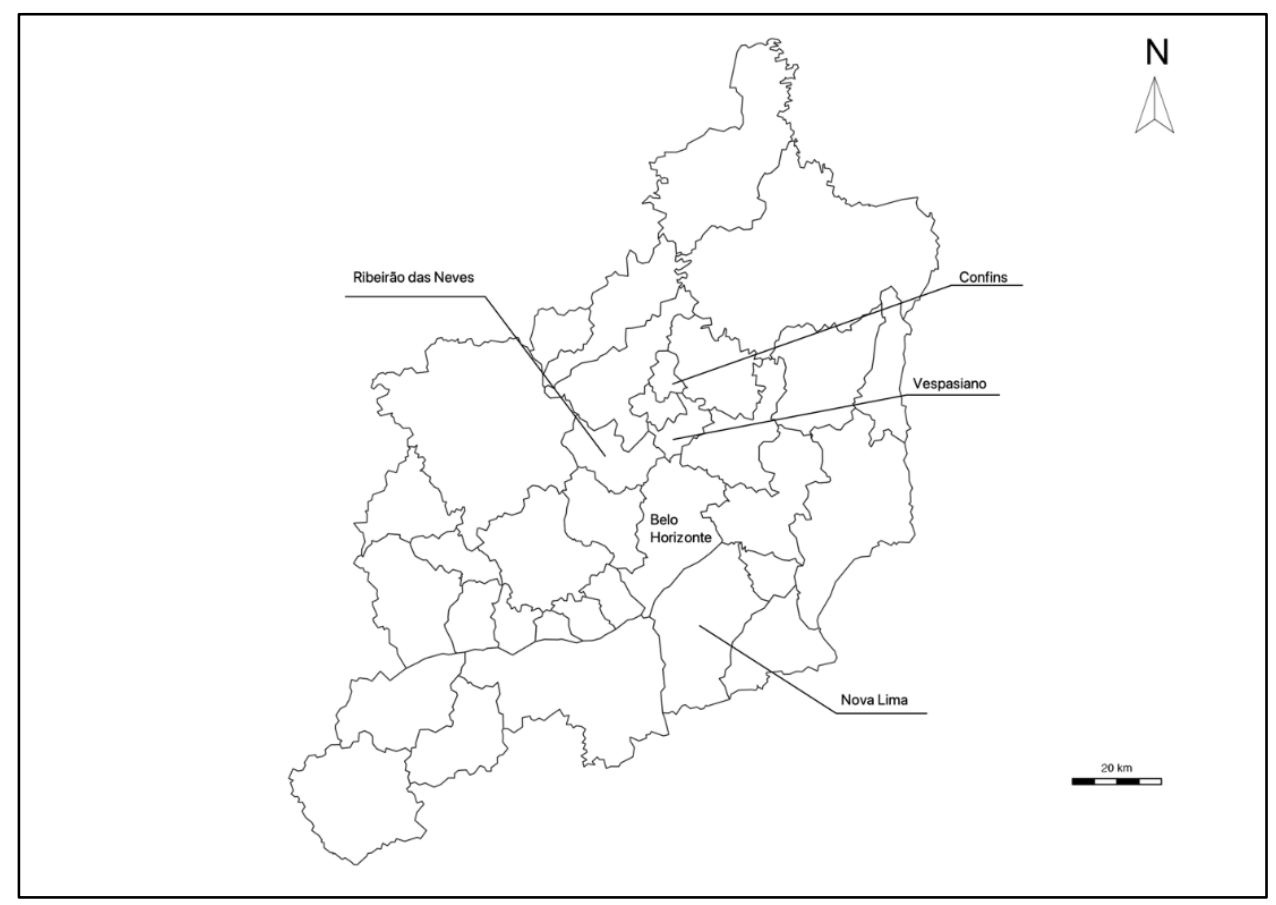

Figura 3 - Municípios de realização das entrevistas. 


\subsection{Amostra de Participantes}

A amostra foi realizada visando um equilíbrio entre participantes do sexo masculino e feminino, assim como faixas etárias e nível de estudo. Além disso, uma condição imperativa da pesquisa consistiu em entrevistar participantes que residissem em diferentes municípios da RMBH, a fim de ilustrar as condições desiguais de mobilidade e infraestrutura das periferias metropolitanas. Registrou-se um número maior de mulheres (18) do que de homens (12) na amostra (Tabela 1). A idade dos entrevistados variou de 18 a 80 anos. Vinte e três participantes encontravam-se empregados no momento da pesquisa, três eram estudantes, três aposentados e apenas um participante encontravase desempregado. Aproximadamente três-quartos dos entrevistados integravam domicílios possuindo ao menos um automóvel. Todos os níveis de escolaridade foram representados na amostra, sendo que um terço dos participantes tinham educação superior.

Tabela 1: Descrição dos entrevistados

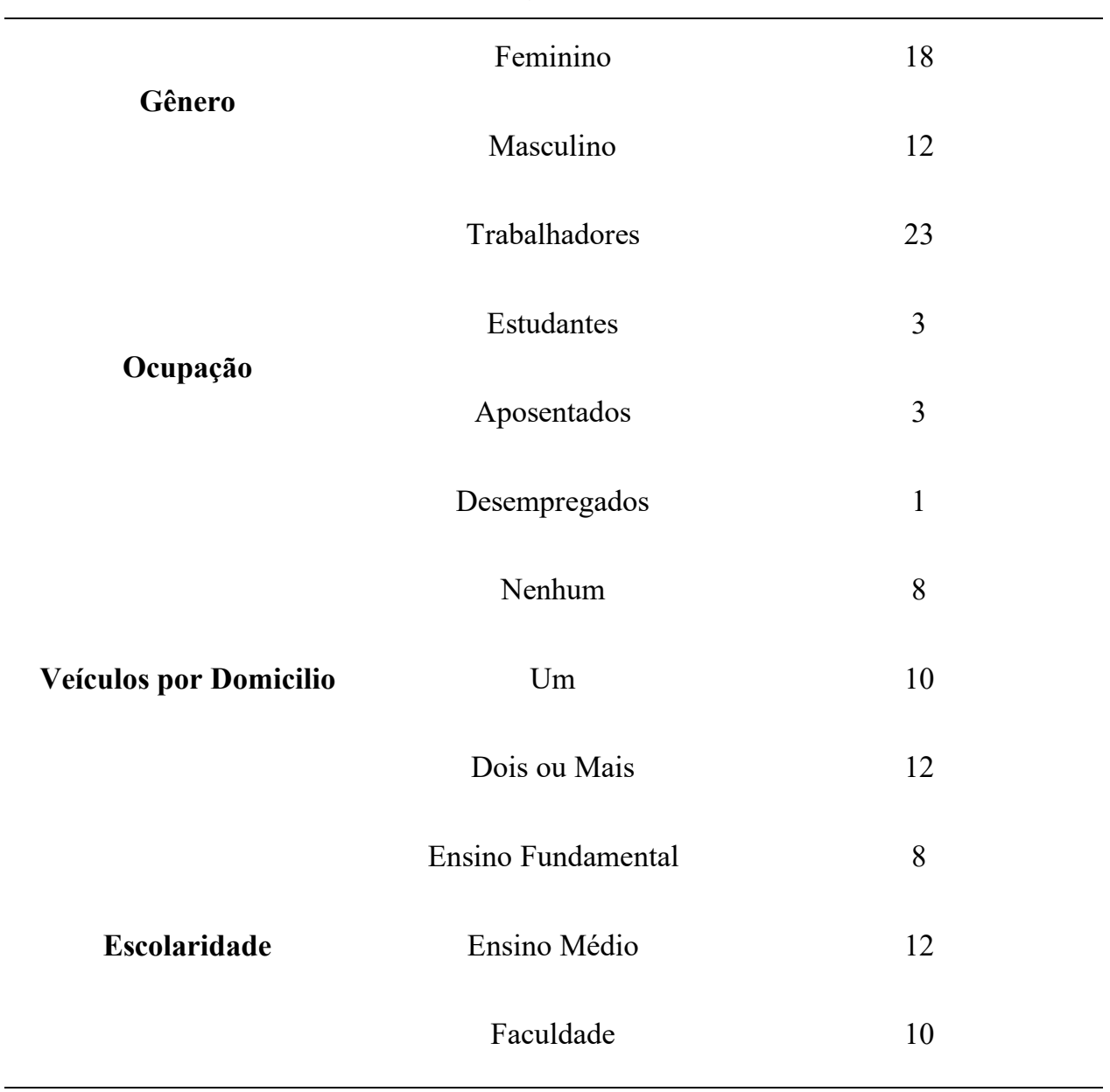

\subsection{Entrevistas}

As entrevistas semiestruturadas, orientadas por um roteiro de entrevista pré-definido, duraram, em média, entre 20-30 minutos. Os participantes foram interrogados acerca de três temas 
principais. Primeiramente, questionou-se a trajetória residencial dos participantes, identificando a localização residencial anterior dos indivíduos e os motivos que determinaram a mudança para o atual local de residência. Posteriormente, os entrevistados relataram os principais deslocamentos efetuados habitualmente, detalhando fatores como os meios de transporte utilizados, as durações médias de cada viagem e os principais motivos de deslocamento. Por fim, os participantes foram convidados a descrever as principais transformações observadas no município de residência, nos últimos anos, (como, por exemplo, a implantação de novas atividades e serviços) e os eventuais impactos de tais mudanças nos comportamentos de mobilidade. Para obter mais informações sobre os participantes, foi solicitado o preenchimento de um questionário, que incluía algumas informações básicas como idade, renda, ocupação, propriedade de veículo e carteira de motorista. Vale lembrar que a identidade dos entrevistados foi anonimizada através de pseudônimos.

\section{RESULTADOS E DISCUSSÕES}

\subsection{O Comportamento de indivíduos de alta renda: uma mobilidade "à la carte"}

As entrevistas assinalam que os deslocamentos realizados por indivíduos de média e alta renda tendem a ser substancialmente influenciados por escolhas, preferências e hábitos pessoais. Os habitantes em questão tendem, não somente a se deslocar com mais frequência e a percorrer maiores distâncias que outros indivíduos, mas também escolher os destinos dos deslocamentos com base em preferências individuais em detrimento a fatores objetivos, como distância ou número de serviços disponíveis. Consequentemente, as populações de alta renda apresentam uma gama mais variada de motivos de deslocamento, como múltiplas atividades culturais e recreativas.

Essa flexibilidade nos padrões de mobilidade e acesso aos serviços articula-se diretamente à posse de um automóvel, que amplia os aspectos espaciais e temporais da mobilidade, permitindo uma busca mais extensa por bens e serviços (CLIFTON, 2004) Os padrões de deslocamento e mobilidade descritos associam-se, intimamente, ao que Chalas (2000) define como "mobilidade à la carte". Com efeito, a totalidade dos indivíduos de renda média e alta entrevistados integram um domicílio possuindo pelo menos dois carros. Assim, a maioria dos entrevistados revela que o fato de percorrer longas distâncias para frequentar um estabelecimento de preferência (lazer, compras, esportes) não é, habitualmente, interpretado como um obstáculo: "Eu geralmente saio com meus amigos em Belo Horizonte, em bares, boates etc. Mas às vezes eu também vou em restaurantes e boates em Nova Lima também [..] é tranquilo porque eu tenho carro, então eu posso ir em qualquer lugar, né?" (Felipe, arquiteto, 28 anos, Nova Lima).

Além disso, a qualidade dos serviços é considerada como um fator determinante dos deslocamentos dos grupos de classe média e alta. Os participantes se demonstram dispostos a 
percorrer maiores distâncias e aumentar os tempos de deslocamento, a fim de acessar atividades consideradas por eles como de melhor qualidade do que os serviços disponíveis na escala local. A lógica de preferências descrita acentua-se, particularmente, no que concerne às atividades de saúde e lazer, para as quais a qualidade muitas vezes aparece como um fator capital (PENCHANSKY; THOMAS, 1981)

Sim, tem atividades de lazer para as crianças dentro do condomínio onde eu moro, mas eu prefiro levar eles no Minas (clube de lazer situado em Belo Horizonte), mesmo que seja mais longe de onde eu moro. Nós somos sócios lá e acaba sendo mais barato quando você tem três filhos. Além disso, é o melhor clube de BH, eles têm tudo! (Vitória, esteticista, 40 anos, Nova Lima)

Consequentemente, as populações de alta renda parecem ter uma relação mais expressiva com o município de Belo Horizonte do que outros moradores, uma vez que o núcleo da cidade apresenta uma maior densidade e diversas opções de atividades e serviços. Moradores de Nova Lima enfatizam que, embora tenha havido um aumento expressivo no número de serviços e comércios locais no município nos últimos anos, eles ainda optam por se deslocar até Belo Horizonte para realizar determinadas atividades, de acordo com preferências pessoais: "Eu conservei os meus médicos todos aqui em BH, com exceção do Biocor, alguns já atendem lá. Mas no geral eu prefiro continuar a ir em BH mesmo, porque eu já conheço eles, já estou acostumada." (Letícia, psicóloga, 68 anos, Nova Lima).

Vale ressaltar que a relação das populações de alta renda com o centro da cidade não é interpretada como uma relação de dependência, pois os moradores afirmam, igualmente, possuir uma gama significativa de escolhas de serviços e atividades na escala local. Sob essa ótica, muitas vezes, desenvolvem-se padrões de mobilidade diversificados e complexos, que articulam deslocamentos de longa distância com uma mobilidade localmente orientada (Figura 5). 

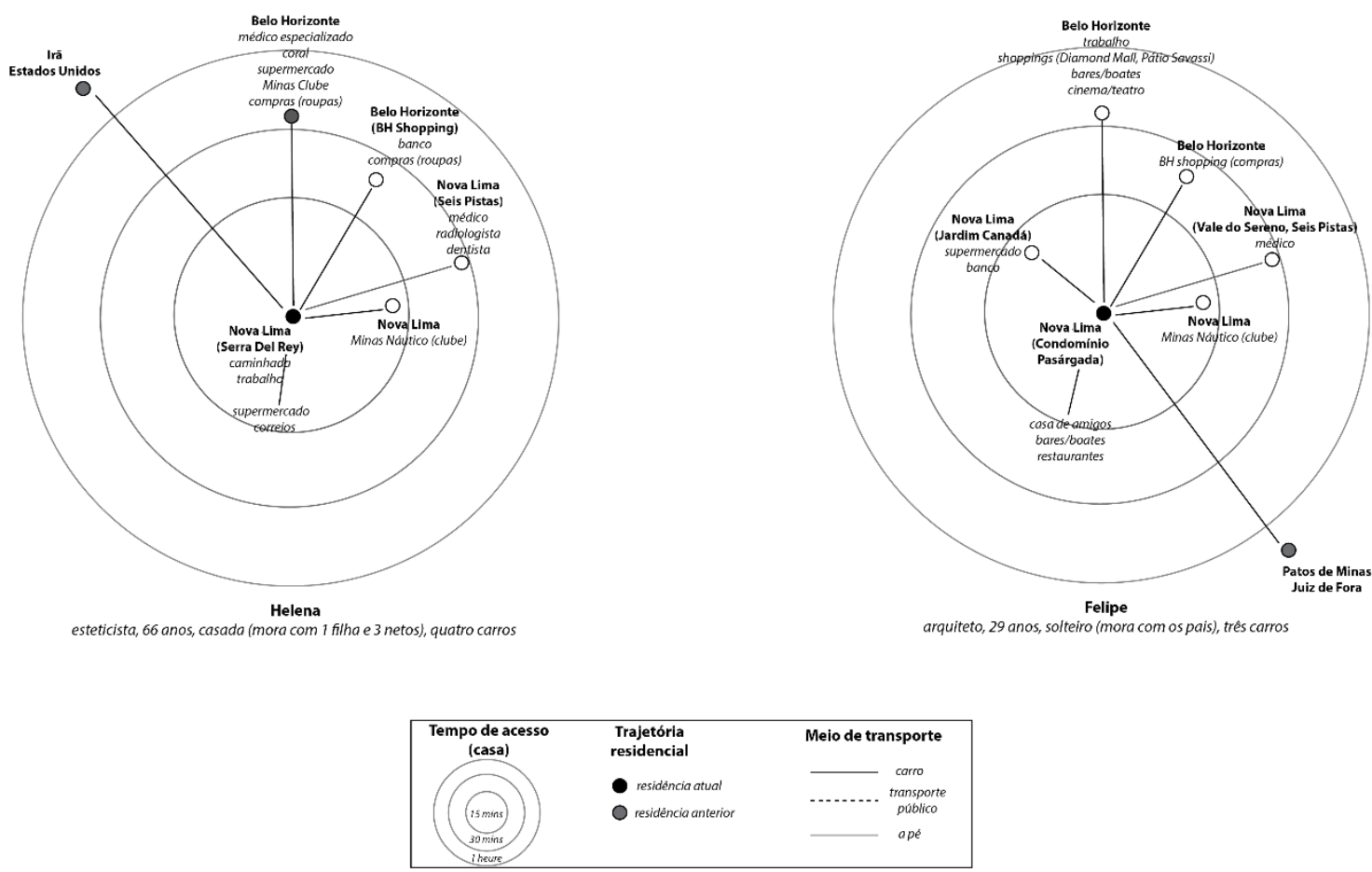

Figura 5 - Exemplos de deslocamento dos participantes de alta renda.

\subsection{O impacto das trajetórias residenciais na mobilidade individual}

As entrevistas revelam que a trajetória residencial para áreas periféricas, frequentemente, é acompanhada por estratégias de mobilidade que remetem ao antigo local de residência. Os novos moradores periféricos relatam dificuldades em se adaptar, inicialmente, ao estilo de vida das periferias, pautado pela menor densidade de serviços e pela necessidade de realizar longos deslocamentos. Assim, para os recém-chegados, o local de residência anterior pode continuar a exercer um papel significativo em termos de mobilidade e destino dos deslocamentos. Beltramone (1975) classifica a transformação dos comportamentos de mobilidade individual após uma mudança residencial como "deslizamento", fenômeno que corresponde a um processo simultâneo de manutenção de algumas atividades no local de residência anterior e desenvolvimento de novos hábitos de deslocamento articulados ao novo local de residência.

Helena, que recentemente se mudou para um condomínio fechado em Nova Lima, ressalta que ainda se desloca, frequentemente, para Belo Horizonte, seu local anterior de residência, para fazer compras. A entrevistada postula que, embora seu novo bairro de residência possua uma quantidade satisfatória de comércios e serviços, o fato de não poder realizar deslocamentos a pé, como em Belo Horizonte, constitui um obstáculo. Helena aponta a dependência do automóvel como uma das principais desvantagens de seu novo local de residência. Nesse sentido, ela afirma preferir fazer 
compras de supermercado em seu antigo bairro de residência, o que requer o traçado de estratégias de mobilidade e horários rigorosos, a fim de otimizar seus deslocamentos ao centro da cidade:

Tem alguns supermercados perto do condomínio onde eu moro, mas pra falar a verdade, ainda não estou completamente acostumada. Quando eu morava em Belo Horizonte eu podia ir andando até o supermercado. Agora, fazer compras depende das oportunidades que eu tenho. Por exemplo, eu canto em um coral uma vez por semana em Belo Horizonte, então eu tento fazer todas as compras de supermercado lá. O coral começa às 18:30 e eu saio de casa por volta das 15:30 para passar no supermercado antes. É complicado você sair do condomínio o tempo todo e dirigir 5, 10 quilômetros para comprar pão, leite. (Helena, esteticista, 68 anos, Nova Lima).

\subsection{As populações de baixa renda: entre a escassez da oferta de infraestrutura transporte e serviços locais}

Os indivíduos de baixa renda entrevistados mostram um acúmulo de limitações em termos de mobilidade, decorrentes de diversos fatores, como capital financeiro limitado, dependência do transporte público e concentração de atividades em determinadas áreas do espaço urbano. Tais categorias tendem a se orientar em torno das atividades do domicílio, uma vez que seu capital financeiro não permite a realização das mesmas atividades efetuadas pelas populações de alta renda, como atividades culturais (museus, cinema, teatro) ou esportivas (ROUGÉ, 2005). Nesse sentido, os baixos níveis de mobilidade e a escassez de meios financeiros traduzem-se em uma importante limitação não somente do número, mas também da distância dos deslocamentos individuais. Os padrões relatados corroboram investigações previamente realizadas, que postulam que moradores de baixa renda das periferias urbanas tendem a desenvolver uma expressiva dependência local em termos de mobilidade (CLIFTON, 2004).

Os participantes relatam que a baixa qualidade e eficiência do transporte público dificulta o deslocamento e o acesso aos serviços básicos. A falta de acesso ou o acesso limitado a um automóvel é frequentemente mencionado como um dos principais obstáculos de mobilidade. Por outro lado, a maioria dos entrevistados avalia o transporte público como inadequado e pouco eficiente, e os deslocamentos a pé são apontados como uma das únicas opções de mobilidade na escala local (Figura 6). Um dos principais argumentos utilizados pelos moradores para justificar as limitações de mobilidade constatadas consiste na relação distância-tempo para o acesso às atividades situadas no centro:

Shopping de jeito nenhum! Eu faço o seguinte, se eu precisar ir no shopping eu tenho que fazer o mesmo trajeto que pra ir pro trabalho, mas quando eu penso que eu tenho que pegar quatro conduções no shopping aí eu já desisto, não vou. Se eu preciso de alguma coisa eu já vou no centro. Eu de verdade, pelo meu trajeto, eu desisto de passear, de sair, eu fico em casa mesmo. (Carmen, 45 anos, zeladora, Vespasiano) 


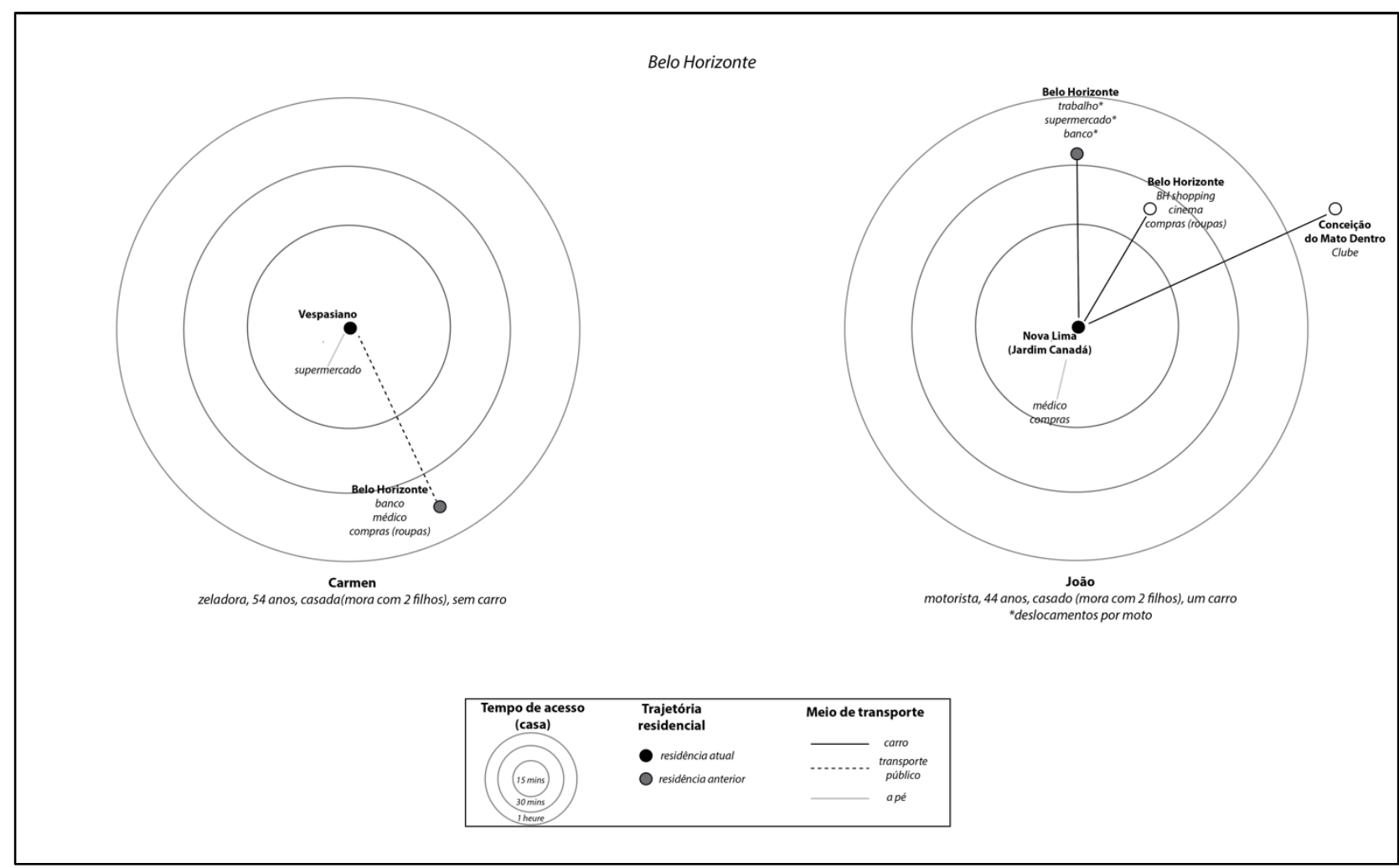

Figura 6 - Exemplos de deslocamento dos participantes de baixa renda.

Vale ressaltar que as populações de alta e baixa renda possuem uma relação diametralmente oposta com o centro de Belo Horizonte. Os primeiros deslocam-se com mais frequência para o centro da cidade e frequentam um leque mais amplo de atividades, enquanto os últimos associam o município de Belo Horizonte, prioritariamente, a deslocamentos obrigatórios, como trabalho e consultas médicas.

Ademais, dentre os entrevistados de baixa renda que possuem um veículo particular, o uso do automóvel é limitado. Com efeito, o gasto financeiro necessário para a utilização cotidiana de um veículo particular revela-se demasiadamente oneroso, para famílias de baixa renda, demandando trocas e sacrifícios financeiros (CLIFTON, 2004). Assim, o uso do automóvel é, muitas vezes, restrito a atividades específicas: "Pra trabalhar, eu uso a moto e pro lazer, por exemplo pra ir no cinema com meus filhos, eu pego o carro. Então o carro acaba sendo mais no final de semana mesmo. A gente tem sempre que fazer o máximo de economia, não é? ” (João, 44 anos, motorista, Nova Lima).

\subsection{A idade: um fator de restrição da mobilidade dos habitantes das periferias}

Além de fatores financeiros, outras características individuais, como a idade, também podem desenhar obstáculos de mobilidade para os moradores das periferias urbanas. As entrevistas apontam que idosos enfrentam diversos obstáculos de mobilidade diretamente associados à idade. $\mathrm{O}$ envelhecimento acarreta um processo paradoxal no qual os indivíduos se tornam gradualmente 
dependentes de um automóvel para se deslocarem, mas, eventualmente, deficiências físicas e cognitivas tendem a dificultar a capacidade de direção (BERGER et al., 2010) :

Morar em um condomínio fechado é muito bom, mas principalmente para os jovens. Enquanto eu ainda sou capaz de dirigir, tudo bem, mas o dia em que eu não puder mais dirigir eu tenho certeza que vou me sentir como um pássaro preso em uma gaiola de ouro. E eu vou ter que pedir aos meus filhos para me levarem onde eu quiser ir. (Helena, esteticista, 68 anos, Nova Lima).

Além disso, os jovens entrevistados relatam, igualmente, dificuldades observadas no que diz respeito ao acesso aos serviços, destacando a importância da obtenção da carteira de motorista. Jovens moradores de espaços periféricos, muitas vezes, dependem dos pais ou de outros adultos para se deslocarem, principalmente, quando existem poucas atividades acessíveis a pé ou por transporte público. De acordo com DIDIER-FÈVRE (2013), para jovens e adolescentes, a construção de uma rede social pessoal consiste em uma etapa fundamental do processo de distanciamento dos pais e de traçado da personalidade individual. Nesse sentido, o estilo de vida associado às periferias pode representar um obstáculo ao processo de desenvolvimento pessoal dos adolescentes, uma vez que a escassez de atividades e as restrições de mobilidade podem ser traduzidas em uma menor quantidade de interações sociais.

Eu tirei minha carteira de motorista há pouco tempo e posso dizer que minha vida mudou. Antes, eu só podia sair quando meus pais podiam me levar, mas agora posso pegar o carro do meu pai emprestado para sair com meus amigos nos fins de semana [..] Eu sempre vou para $\mathrm{BH}$ com meus amigos porque a gente gosta de ir no shopping. Nos sábados tem alguns ônibus que descem para o centro, mas o horário não é tão bom: tem um ônibus de manhã e depois outro à noite. As poucas vezes que tive que pegar o ônibus para encontrar meus amigos, eu tive que voltar para casa muito cedo. Mas agora que eu tenho minha carteira tenho muito mais autonomia! (Lucas, estudante, 18 anos, Nova Lima)

\subsection{Empréstimo de automóvel e serviços de delivery: alternativas para mitigar as limitações de mobilidade}

Na seção anterior, enfatizou-se que diversas famílias de baixa renda optam por restringir a quantidade e distância de deslocamentos realizados, devido a restrições de mobilidade e acesso aos serviços. No entanto, vale ressaltar que, alguns entrevistados mencionam estratégias traçadas a fim de ampliar o número e a distância dos deslocamentos realizados. Indivíduos cujo domicílio não possui um automóvel particular, descrevem uma pluralidade de alternativas utilizadas para mitigar as limitações de mobilidade, como caronas de amigos e familiares, empréstimo de veículos ou uso de táxis. A entrevistada Fernanda relata que foi necessário vender o carro de seu domicílio para pagar o tratamento médico do marido. Atualmente, ela afirma pegar emprestado o carro da amiga, frequentemente: "Minha vida mudou muito depois que vendemos nosso carro. Às vezes, eu e meu marido queremos sair no final de semana, mas minha família nunca pode, então peço aos meus 
amigos pra dar uma carona ou pra pegar o carro emprestado." (Fernanda, doméstica, 41 anos, Ribeirão das Neves).

Além disso, com a recente evolução dos serviços de entrega a domicílio, alguns entrevistados optam conscientemente por fazer sacrifícios financeiros. Carmen descreve que a escassez de supermercados em seu bairro, em Vespasiano, acarreta dificuldades de mobilidade. Recentemente, a entrevistada optou por recorrer a serviços de delivery de compras, como forma de evitar os longos deslocamentos ao supermercado:

\begin{abstract}
Para mim, morar na periferia é muito complicado. Eu não tenho carro e no meu bairro não tem supermercado perto da minha casa. Eu costumava andar um quilômetro até o supermercado e depois eu tinha que voltar com um monte de sacola pesada pesados. Era difícil porque as ruas são muito íngremes. Então, um dia eu decidi que eu ia começar a pedir pra entregar as compras em casa. É mais caro, mas ao menos eu não preciso mais ir ao supermercado. (Carmen, zeladora, 52 anos, Vespasiano)
\end{abstract}

\title{
4.6. A disseminação de condomínios fechados: quais impactos na mobilidade?
}

Os primeiros resultados expostos demonstram que, ainda que os moradores de alta renda das periferias apresentem padrões diversificados de mobilidade, o desenvolvimento de condomínios fechados tem contribuído com a reestruturação da mobilidade na escala local. Nas últimas duas décadas, a expansão urbana em Belo Horizonte caracterizou-se pela proliferação de loteamentos residenciais fechados, sobretudo nas periferias do Vetor Sul. Consequentemente, o aumento de loteamentos de alta renda, nas áreas em questão, corroborou a implementação de atividades e serviços nas adjacências dos condomínios, configurando novas centralidades periféricas. Além disso, os referidos empreendimentos residenciais incorporaram, igualmente, uma série de amenidades privadas, como atividades de lazer, comércio e serviços básicos.

A maioria dos participantes deste estudo ressalta que, nos últimos anos, houve um aumento substancial na quantidade de serviços locais disponíveis nas adjacências dos condomínios:

Agora tem um monte de lojas perto do condomínio onde moro, tem um Supernosso, tem o Vale do Sereno e tem shopping novo também. Quando me mudei para cá, 30 anos atrás, se precisasse de algo, tinha que ir a Belo Horizonte. Agora tem praticamente tudo o que eu preciso aqui perto! (Afonso, aposentado, 64 anos, Nova Lima).

Nesse contexto, muitas vezes, os moradores de condomínios fechados, afirmam limitar seus deslocamentos de forma consciente:

Olha tem tudo ao lado, mas como eu sou muito caseira eu tenho tudo em casa, eu tenho piscina, sauna, galinha, planta, tenho telão. Eu também caminho dentro do condomínio. Eu optei por um estilo de vida e me adaptei a ele porque as circunstâncias me possibilitaram. (Leticia, 68 anos, psicóloga, Nova Lima)

Alguns participantes de baixa renda e de classe média baixa que habitam nas adjacências de condomínios fechados descrevem as transformações recentes como positivas. Os resultados em 
questão reproduzem investigações prévias no sentido de que, ainda que a difusão de condomínios fechados acentue a segregação na escala local, observa-se que o referido modelo de ocupação incentiva o desenvolvimento de serviços locais, contribuindo, consequentemente, com a reconfiguração dos comportamentos de mobilidade: "A gente mora no Jardim Canadá e eu te falo que o bairro tem se desenvolvido muito nos últimos anos. Tem dois supermercados novos, cabeleireiro e um pet shop. (João, 44 anos, motorista, Nova Lima). Entretanto, o aumento da população de alta renda nas periferias contribui com um acréscimo significativo dos custos dos serviços locais, excluindo, assim, os moradores de baixa renda historicamente presentes nas áreas em questão: "Eu geralmente faço compras em BH, porque em Nova Lima é muito caro. Eu vou de moto para o trabalho e faço as compras na volta." (João, 44 anos, motorista, Nova Lima).

Contrariamente às periferias de alta renda, moradores de bairros de baixa renda afirmam não ter notado nenhuma evolução significativa na quantidade de serviços locais, fator que se revela problemático em termos de mobilidade: "Eu sinto é que o comércio e as atividades de lazer estão desaparecendo! Não tem lugares para sair e se divertir! Se eu quiser sair, preciso pegar o carro e ir até Belo Horizonte, que fica a 40 minutos daqui. Mesmo que o aeroporto tenha sido modernizado recentemente, eu sinto como se essa modernização não tivesse chegado na gente. É uma pena, porque moramos perto." (Pedro, dono de bar, 35 anos, Confins).

\subsection{As evoluções das condições de mobilidade nas periferias: uma insatisfação generalizada dos usuários de transporte público}

Os entrevistados foram, igualmente, questionados sobre as evoluções relativas à mobilidade constatadas nos últimos anos. A grande maioria dos participantes ressalta que as condições de mobilidade e deslocamento se deterioraram consideravelmente na Região Metropolitana nos últimos anos. Paula (professora, 27 anos, Nova Lima) aponta que, apesar do aumento na oferta de atividades e serviços em Nova Lima, a qualidade dos deslocamentos degradou-se nos últimos anos: “ $A h, o$ trânsito piorou muito. Tem muito mais pessoas morando em Nova Lima agora. Mesmo os ônibus, parece que tem menos ônibus e mais atrasos."

Além disso, o sistema de BRT implementado na última década, o MOVE, foi unanimemente criticado pelos usuários entrevistados, devido a um aumento dos tempos e distâncias de deslocamento decorrentes da remoção de várias linhas de ônibus que permeavam bairros periféricos. $\mathrm{O}$ sistema Transporte Rápido por Ônibus, MOVE, inaugurado em 2014, é constituído por uma rede de corredores exclusivos e estações integradas, ao longo das avenidas Antônio Carlos, Cristiano Machado, Paraná, Pedro I, Santos Dumont e Vilarinho, realizando uma conexão entre o hipercentro e o Vetor Norte da RMBH. Atualmente, para parte dos moradores entrevistados, o MOVE é a única alternativa disponível de transporte público para acessar o centro da cidade. As entrevistas assinalam 
que os moradores das periferias do Vetor Norte da metrópole tendem a ser os mais afetados pelas recentes mudanças no sistema de transporte público. Raquel (doméstica, 43 anos, Ribeirão das Neves) ressalta que desde a inauguração do MOVE, foi necessário realizar uma adaptação em seu trajeto, que adicionou uma linha de ônibus a mais no deslocamento casa-trabalho, totalizando seis ônibus por dia. Da mesma forma, Carmen fornece longo testemunho sobre as condições de deslocamento observadas no MOVE:

Eu faço baldeação todo o dia no centro para ir trabalhar no centro e vou ser sincera com você. Esse MOVE é desumano [..] é horrível, está sempre lotado e as pessoas são muito sem educação! Se eu perder o ônibus das 17:30 o próximo que me leva para casa não passa antes das 18:20. Antes eu só pegava dois ônibus, agora são três [..] antes eu levava 50 minutos para chegar em casa e agora eu levo duas horas! No começo, quando inauguraram o MOVE, eu chegava em casa e chorava. Antes quando eu pegava o ônibus era tranquilo, eu podia sentar, eu não ligava tanto pro trajeto. Mas agora, com o MOVE, eu me sinto uma sardinha espremida dentro do ônibus. Ah, eu te digo que eles não pensaram muito na população não! (Carmen, zeladora, 50 anos, Vespasiano).

\section{CONSIDERAÇÕES FINAIS}

O presente estudo demonstra que, apesar da emergência de novas estruturas socioespaciais na Região Metropolitana de Belo Horizonte, a mobilidade dos moradores das periferias metropolitanas ainda é pautada por lógicas de intensa desigualdade. Os resultados indicam que a dependência da mobilidade automóvel ainda consiste em um fator determinante no acesso aos serviços nas periferias urbanas. As populações de alta renda, habitualmente proprietárias de ao menos um veículo particular, apresentam padrões de mobilidade multifacetados, percorrendo maiores distâncias e realizando uma quantidade maior de deslocamentos baseados em preferências individuais.

Por outro lado, integrantes de domicílios desprovidos de um veículo particular tendem a ser altamente dependentes do sistema de transporte público, avaliado pelos entrevistados como ineficiente e pouco confiável. A maioria dos moradores de bairros de baixa renda opta por limitar a quantidade e a distância dos deslocamentos realizados. Esse cenário de dependência local impõe diversos obstáculos significativos de mobilidade e acesso aos serviços, uma vez que as áreas de baixa renda tendem a apresentar uma oferta limitada de atividades. Nesse sentido, demonstra-se que, frequentemente, os habitantes das periferias metropolitanas traçam estratégias a fim de mitigar os obstáculos de mobilidade observados, como o empréstimo de veículos ou a utilização de serviços de entrega.

Demonstra-se, ainda, que as transformações socioespaciais observadas nas periferias urbanas nas últimas décadas impactaram diretamente a mobilidade de alguns grupos de habitantes das periferias urbanas. Os habitantes de condomínios fechados do vetor sul da RMBH destacam que o desenvolvimento de atividades na escala local nas últimas décadas, permitiu uma reconfiguração 
da dependência histórica do centro de Belo Horizonte. Com efeito, os moradores apontam que a emergência recente de serviços locais, tais como padarias, supermercados e atividades de lazer, permitem evitar os deslocamentos mandatórios ao centro de Belo Horizonte. Em contrapartida, os habitantes de áreas de baixa renda ressaltam que as periferias menos desenvolvidas foram pouco contempladas pelas mudanças em questão, destacando os inúmeros desafios de mobilidade enfrentados no cotidiano e a dependência do município de Belo Horizonte no que concerne o acesso a serviços cotidianos, como emprego, saúde e lazer. Além disso, os moradores das periferias de baixa renda apontam a ineficácia das melhorias dos serviços de transporte na última década, particularmente do sistema de BRT MOVE, que tornou os deslocamentos diários mais longos e penosos. Os resultados sublinhados convergem com investigações previamente realizadas em outras cidades da América Latina (LUKAS; LÓPEZ-MORALES, 2018).

Embora os documentos de planejamento norteadores da expansão da RMBH, como Plano Diretor de Desenvolvimento Integrado e o Plano de Mobilidade Metropolitano, caminhem na direção da elaboração de medidas visando a melhoria das condições de mobilidade urbana e acesso aos serviços em uma escala metropolitana, as diretrizes preconizadas ainda apresentam poucos impactos sobre as condições de deslocamento dos habitantes das periferias urbanas. Nesse sentido, parece imperativa a necessidade de um planejamento integrado a nível metropolitano, assinalando o caráter heterogêneo e plural dos espaços periféricos e ultrapassando a abordagem binária de dependência entre centro e periferias.

\section{REFERÊNCIAS}

ALMEIDA, R. P.; MONTE-MÓR, R. L. MELO.; AMARAL, P. V. M. Implosão e explosão na Exópolis: evidências a partir do mercado imobiliário da RMBH. Nova Economia, v. 27, n. 2, p. 323$350,2017$.

ANDRADE, L.; MENDONÇA, J.; DINIZ, A. Belo Horizonte: transformações na ordem urbana. Rio de Janeiro: Letra Capital: Observatório das Metrópoles, 2015. 474p.

BACQUÉ, M.-H.; FOL, S. L'inegalité face à la mobilité: du constat à l'injonction. Revue Suisse de Sociologie, v. 33, n. 1, p. 89-104, 2007.

BELTRAMONE, A. Définition logique des flux migratoires intérieurs. Migrations intérieures, $p$. 491-518, 1975.

BERGER, M.; ROUGÉ, L.; THOMANN, S.; THOUZELLIER, C. Vieillir en pavillon : mobilités et ancrages des personnes âgées dans les espaces périurbains d'aires métropolitaines (Toulouse, Paris, Marseille). Espace populations sociétés, n. 2010/1, p. 53-67, 2010.

BERROIR, S.; DELAGE, M.; FLEURY, A.; FOL, S.; GUÉROIS, M.; MAULAT, J.; RAAD, L.; VALLÉE, J.; CERQUEIRA, E. V. Petites villes périurbaines et ancrage local des habitants. Les cas de Méru et Senlis dans l'Oise. Espaces et sociétés, n. 1, p. 69-88, 2017. 
CHALAS, Y. L’invention de la ville. Paris: Anthropos : Diffusion Economica, 2000. 176p.

CLIFTON, K. J. Mobility Strategies and Food Shopping for Low-Income Families: A Case Study. Journal of Planning Education and Research, v. 23, n. 4, p. 402-413, 2004.

CLIFTON, K. J.; HANDY, S. L. Qualitative methods in travel behaviour research. In: JONES, P.; STOPHER, P. R. (Ed.) Transport survey quality and innovation. Emerald Group Publishing Limited, 2001. p. 283-302.

COSTA, H. S.; MENDONÇA, J. G. Novidades e permanências na produção do espaço da metrópole: um olhar a partir de Belo Horizonte. In: ANDRADE, L. T.; MENDONÇA, J. G.; DINIZ, A. M. A. (Eds.). Belo Horizonte: transformações na ordem urbana. Rio de Janeiro: Letra Capital, 2015. 4665 .

COSTA, H. S.; MENDONÇA, J. G. Urbanização recente e disputa pelo espaço na dinâmica imobiliária metropolitana em Belo Horizonte. In: ENCONTRO NACIOANL DE ESTUDOS POPULACIONAIS. 27., 2010, Caxambu. Anais... Caxambu, 2010.

DIDIER-FÈVRE, C. Être jeune et habiter les espaces périurbains: la double peine? Géo-Regards: Revue Neuchâteloise de Géographie, p. 35-52, 2013.

DUPUY, G. La dépendance automobile : symptômes analyses, diagnostics. Paris: Anthropos, 1999. $163 p$.

FOL, S. Mobilité et ancrage dans les quartiers pauvres: les ressources de la proximité. Regards sociologiques, n. 40, p. 27-43, 2010.

HARRIS, R.; VORMS, C. (Eds.). What's in a Name?: Talking about Urban Peripheries. Toronto: University of Toronto Press, 2017. 376p.

LE GOIX, R. Sur le front de la métropole: une géographie suburbaine de Los Angeles. Paris: Publications de la Sorbonne, 2016. 318p.

LEFEBVRE, H. Le droit à la ville. Paris: Anthropos, 1968. 146p.

LESSA, D. A.; LOBO, C.; CARDOSO, L. Accessibility and urban mobility by bus in Belo Horizonte/Minas Gerais - Brazil. Journal of Transport Geography, v. 77, p. 1-10, 2019.

LIMONAD, E.; COSTA, H. S. M. Cidades excêntricas ou novas periferias? Revista Cidades, v. 12, n. 21, p. 278-304, 2015.

LUKAS, M.; LÓPEZ-MORALES, E. Real estate production, geographies of mobility and spatial contestation: A two-case study in Santiago de Chile. Journal of Transport Geography, v. 67, p. 92-101, 2018.

MAGAGNIN, R. C. A percepção do especialista sobre o tema mobilidade urbana. Transportes. v. 16, n. 1, p. 25-35, 2008.

MENDONÇA, J. G.; PERPÉTUO, I. H. O.; VARGAS, M. C. A Periferização Da Riqueza Na Metrópole Belo-Horizontina: Falsa Hipótese?. In: SEMINÁRIO SOBRE A ECONOMIA MINEIRA. 11., 2004, Diamantina. Anais... Diamantina, 2004. 
NETO, V. C. L.; FILHO, R. D. O. A Governança Metropolitana da Mobilidade: uma Análise a partir dos Estados. Brasília: IPEA, 2015. GOVERNANÇA METROPOLITANA DA MOBILIDADE: UMA ANÁLISE A PARTIR DOS ESTADOS. Brasília: IPEA, 2015. 56p.

PENCHANSKY, R.; THOMAS, W. The concept of Access Definition and Relationship to Consumer Satisfaction. Medical Care, v. 19, n. 2, p. 127-140, 1981.

PHELPS, N. A. In what sense a post-suburban era? In: HANLON, B.; VICINO, T. J. (Eds.). The Routledge Companion to the Suburbs. London \& New York: Routledge, 2018. p. 39-47.

REIS FILHO, N. Notas sobre urbanização dispersa e novas formas de tecido urbano. São Paulo: Via das Artes, 2006. 201p.

ROUGÉ, L. Les « captifs » du périurbain. Voyage chez les ménages modestes installés en lointaine périphérie. In: CAPRON, G.; GUETAT, H.; CORTES, G. (Eds.). Liens et lieux de la mobilité. Paris: Belin ed. p. 129-144.

TONUCCI FILHO, J. B. M.; MEDEIROS DE FREITAS, D. Planejamento metropolitano e grandes projetos urbanos: concepção e descaminhos da política de novas centralidades na RMBH. Cadernos Métropole, v. 22, n. 47, p. 61-84, 2019.

VIANA CERQUEIRA, E. D. As desigualdades de mobilidade nas periferias da Região Metropolitana de Belo Horizonte: um estudo das atividades de comércio, lazer e saúde. Cadernos Metrópole, v. 20, n. 41, p. 35-51, 2018. 